\title{
Evidence of local pH changes during ethanol oxidation at Pt electrodes in alkaline media**
}

\author{
Marta C. Figueiredo*, Rosa M. Arán-Ais, Víctor Climent, Tanja Kallio, Juan M. Feliu
}

\begin{abstract}
Local changes of the interfacial $\mathrm{pH}$ can significantly affect the rate and mechanism in the course of an electrodic reaction. For instance, different $\mathrm{pH}$ values will have significant effect on the equilibrium properties of both solution and surface species altering the reactions kinetics. Ethanol oxidation at platinum electrodes, in alkaline media involves a fast consumption of $\mathrm{OH}^{-}$species that will change the local $\mathrm{pH}$ at the electrode surface decreasing the reaction rate. In this study, the local $\mathrm{pH}$ change during ethanol oxidation in alkaline media is accomplished by using rotating ring disc electrode (RRDE) experiments. The current at the ring when polarised at the onset of hydrogen evolution, serves as a measure of the local $\mathrm{pH}$ in the vicinity of the electrode. The results show that the current at the ring at $0.1 \mathrm{~V}$ (vs RHE) becomes more negative during ethanol oxidation due to a change in the equilibrium potential of the hydrogen evolution reaction due to the change in the local $\mathrm{pH}$.
\end{abstract}

Recent advances in the development of anion exchange membranes (AEM) [1-4] have increased the interest in the study of alcohols oxidation for direct alcohol fuel cells (DAFC). The use of high $\mathrm{pH}$ electrolytes in DAFC presents many advantages: the oxidation of organic fuels (such as methanol or ethanol) is faster and takes place at lower overpotentials in alkaline media $[5,6]$; alkaline conditions are also more favourable for the cathodic side (oxygen reduction reaction) [7] and the range of electrode materials that are stable is much wider allowing the use of cheaper and more abundant less noble metals [8].

Though AEM-DAFC are considered as a promising alternative to conventional polymer exchange membrane (PEM) DAFC, there are still many challenges to face in this area. The slow development of AEM-DAFCs seems, at least in part, to be caused by the lack of ideal and robust alkaline membranes. Besides, the $\mathrm{pH}$ changes in the anodic region due to proton release and carbonate formation will thermodynamically cause a voltage loss to the fuel cell [9]. This change of the $\mathrm{pH}$ in the vicinity of the electrode will also affect significantly the catalytic activity of the metal toward the alcohol oxidation reaction.

During reactions involving $\mathrm{H}^{+}$or $\mathrm{OH}^{-}$as reactants or products, the local $\mathrm{pH}$ at the electrode/electrolyte interphase can differ from that in the bulk electrolyte with the progress of the reaction, especially when the electrode processes are much faster than the mass transport $[10,11]$. In turn, the change of the $\mathrm{pH}$ will certainly affect the equilibrium potential and the kinetic

[*] Dr. M. C. Figueiredo ${ }^{\#+}$, Dr. Tanja Kallio

Chemistry Department, Research group of Fuel Cells

Aalto University

P.O. Box 16100, 00076 Aalto, Finland

Fax: +358947022580

\#Current adress: Leiden Institute of Chemistry, Leiden University

PO Box 9502, 2300 RA Leiden, Netherlands

E-mail: marta.figueiredo@aalto.fi

R. Arán-Aís ${ }^{+}$, Dr. Víctor Climent, Prof. J. M. Feliu

Instituto de Electroquímica

Universidad de Alicante

Apartado 99, 03080 Alicante, Spain behavior for such reactions. This phenomenon is particularly important when working under low volume confined environments or thin layer configurations (as in porous electrodes with thicknesses in the range of tens of $\mu \mathrm{m}$ used in fuel cells or during some spectroelectrochemical measurements).

The overall oxidation reaction of ethanol in alkaline media is:

$$
\mathrm{CH}_{3} \mathrm{CH}_{2} \mathrm{OH}+12 \mathrm{OH}^{-} \rightarrow 2 \mathrm{CO}_{2}+9 \mathrm{H}_{2} \mathrm{O}+12 \mathrm{e}^{-} \quad \text { (Eq. 1) }
$$

This reaction involves the consumption of a great amount of $\mathrm{OH}^{-}$species at the electrode and, therefore, it is very likely to produce a change in the local $\mathrm{pH}$ of the solution in contact with the surface of the electrode. This $\mathrm{pH}$ change will be significant if the $\mathrm{OH}^{-}$concentration at the interphase is not replenished by mass transport. Under these conditions, as ethanol oxidation proceeds, the reaction will take place in progressively more acidic solution. There are numerous studies that mention local $\mathrm{pH}$ changes at the electrode surface during ethanol oxidation [12, 13], especially when spectroelectrochemical measurements are reported, in which $\mathrm{CO}_{2}$, and not carbonate, bands can be observed in alkaline media, signaling that local $\mathrm{pH}$ is sufficiently low to preserve the stability of the produced $\mathrm{CO}_{2}$. These changes of $\mathrm{pH}$ will have, as explained before, drastic consequences in fuel cells systems when ethanol is used as fuel.

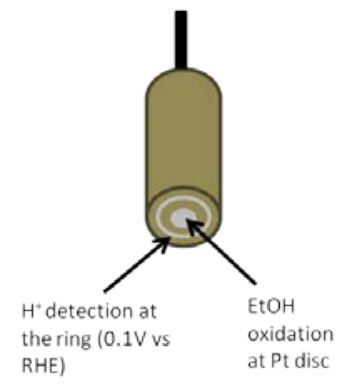

Scheme 1. Rotating Ring Disc electrode set-up used for this study.

In this paper, by using rotating ring disc measurements, we reveal the existence of local $\mathrm{pH}$ changes in the vicinity of a $\mathrm{Pt}$ electrode during ethanol oxidation in alkaline media. This was achieved with a ring-disk system (Scheme 1), by measuring the increase of cathodic currents at the ring at a constant potential of $0.1 \mathrm{~V}$ (caused by the shift of the equilibrium potential of the hydrogen evolution reaction) while the disc potential was cycling in the ethanol oxidation potential range $(0.1$ to $1.25 \mathrm{~V})$. The potential of $0.1 \mathrm{~V}$ for the ring was chosen for two reasons: first, no contributions from the oxidation of ethanol or any other intermediates are expected at $0.1 \mathrm{~V}$ and second, at $\mathrm{pH}$ close to $13(0.1 \mathrm{M} \mathrm{NaOH})$, the surface will be covered by hydrogen at this potential but no hydrogen evolution will occur. However, if local $\mathrm{pH}$ decreases, the onset potential for hydrogen evolution will increase, and this reaction will take place accordingly. 
In this respect, considering the Nernst equation:

$$
E=E_{p H 13}-0.0591 \vee \Delta p H \quad \text { (Eq. 2) }
$$

Where $\Delta \mathrm{pH}$ is $\mathrm{pH}-13, \mathrm{E}$ and $\mathrm{E}_{\mathrm{pH} 13}$ are the equilibrium potential for hydrogen evolution at different $\mathrm{pH}$ values and fugacity of hydrogen has been considered equal to one. Changes of the $\mathrm{pH}$ at the electrode vicinity will lead to a variation of the equilibrium potential and consequently, if the ring electrode potential is kept constant, on the overpotential for the reaction. A decrease of the $\mathrm{pH}$ will increase the equilibrium potential that can reach values above the imposed potential of the ring, creating a negative overpotential that would lead to the production of hydrogen and the increase of current intensities measured at the ring. Conversely, when the equilibrium potential decreases near the electrode due to the lower concentration of protons, the current at the ring from hydrogen evolution will decrease.

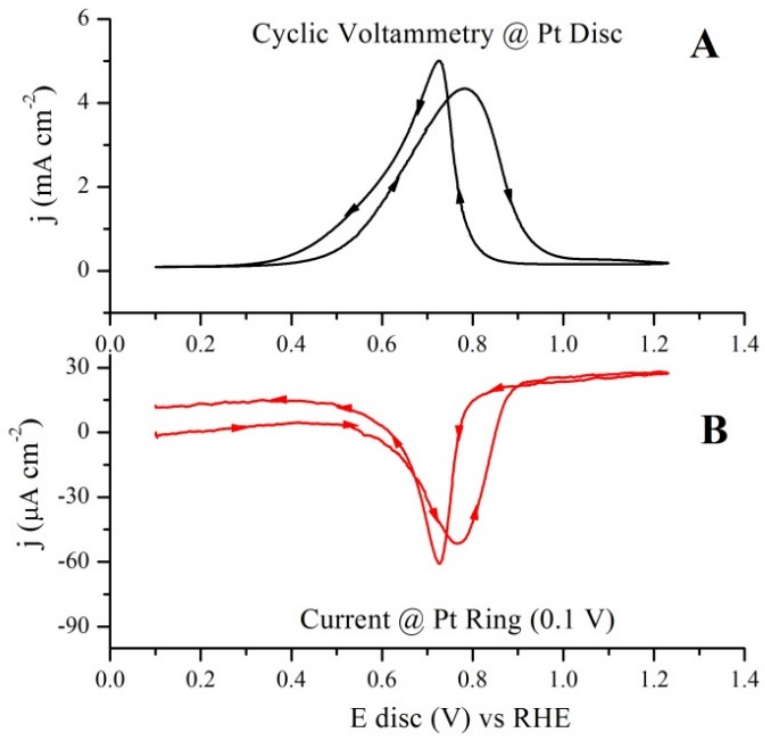

Figure 1. A) Cyclic voltammogram obtained at the Pt disk for $0.1 \mathrm{M}$ ethanol in $0.1 \mathrm{M} \mathrm{NaOH}$ at $10 \mathrm{mV} / \mathrm{s}$ and $1800 \mathrm{rpm}$. B) Currents measured at the Pt ring as a function of the disk potential when the applied potential of the ring is $0.1 \mathrm{~V}$.

The results from these experiments are plotted in Figure 1. In this figure, ring currents are corrected by the collection efficiency, $\mathrm{N}$, defined as the ratio between the ring and disk current in a typical collection experiment in which the product produced in the disk reacts completely when it reaches the ring. The collection efficiency can be calculated from the geometry of the electrodes $[14,15]$. With this correction the different concentration values at the surface of the ring and of the disk is taken into account. Figure 1 clearly shows that, when ethanol oxidation starts at the disc ( $0.5 \mathrm{~V}$ vs RHE), the currents due to hydrogen evolution at the ring start to decrease (increase in absolute value). About $0.8 \mathrm{~V}$ RHE the rate of ethanol oxidation reaches a maximum and then it decreases to nearly zero. The current at the ring describes an almost identical behaviour mirroring the current at the disk. Similar trends are observed both for disc and ring currents in the negative going sweep According to the discussion above, the observation of currents in the ring is a clear indication of a change on the local $\mathrm{pH}$ of the solution near the electrode surface during the oxidation reaction.

It could be argued that the ring current could be due to the reduction of another product (different from $\mathrm{CO}_{2}$ and $\mathrm{H}^{+}$) produced during ethanol oxidation. In particular, acetaldehyde has been reported in the literature to be formed from ethanol oxidation on Pt. If produced, acetaldehyde could be decomposed and reduced to ethane and methane in the same potential region where hydrogen adsorption takes place [16]. In order to rule out this possibility the following experiment was performed: a solution $0.1 \mathrm{M} \mathrm{NaOH}$ (pure electrolyte) was replaced in a flow cell by another containing $0.01 \mathrm{M}$ of acetaldehyde in $0.1 \mathrm{M} \mathrm{NaOH}$ while the potential of the working electrode was kept at $0.1 \mathrm{~V}$. After registering the current during $\sim 75 \mathrm{~s}$ the potential was decreased first to 0.05 and then to $0 \mathrm{~V}$ (vs RHE). The obtained results are presented in Figure 2.

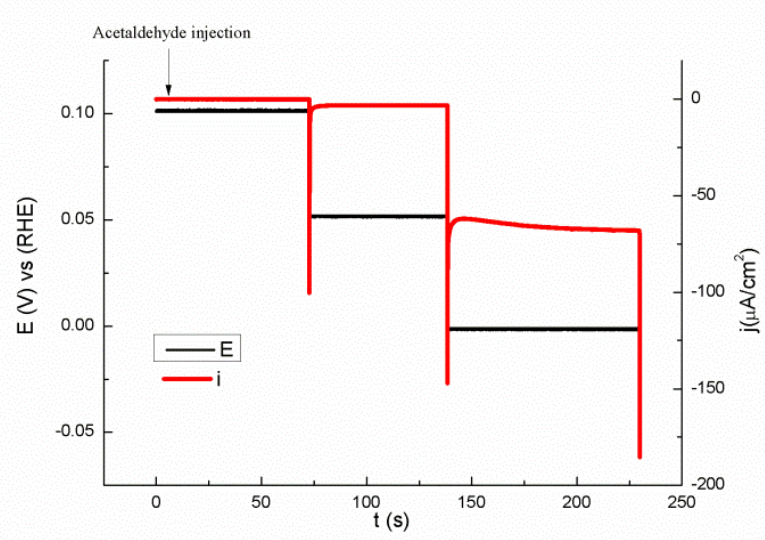

Figure 2. Chronoamperometric curves for acetaldehyde reduction on $\mathrm{Pt}$ in 0.1 $\mathrm{NaOH}$ at $0.1,0.05$ and $0 \mathrm{~V}$ (vs RHE).

The results clearly show that, at $0.1 \mathrm{~V}$ there is no reduction currents on the electrode coming from the addition of acetaldehyde. Only when the electrode potential is decreased to $0.05 \mathrm{~V}$ and $0 \mathrm{~V}$, the reduction of acetaldehyde takes place. From these observations we conclude that the reductive currents observed on the ring at $0.1 \mathrm{~V}$ during ethanol oxidation at the disc are exclusively due to changes on the hydronium concentration on the interphase and, consequently due to the local $\mathrm{pH}$ change.

To give a quantitative measure of the variation of the $\mathrm{pH}$ at the electrode surface, a calibration of the currents obtained at the ring with different potentials was done. For that, the potential of the ring was swept between 0.2 and $-0.1 \mathrm{~V}$ to record the currents during hydrogen evolution in $0.1 \mathrm{M} \mathrm{NaOH}$. Then, the values obtained at the ring during ethanol oxidation were compared with the hydrogen evolution currents and the real equilibrium potential at the electrode surface was found. Figure 3 shows the calibration for hydrogen evolution at the ring as well 
as the explanation for the equilibrium potential determination. In this calculation, it is assumed that the current is only function of the overpotential, i.e., it shifts $59 \mathrm{mV}$ per $\mathrm{pH}$ unit. In order to check validity of this assumption, the hydrogen evolution reaction was performed on polycrystalline platinum at different $\mathrm{pHs}$ ) as show in the inset of Figure 3. As can be observed, both the voltammetric peaks (due to $\mathrm{H}$ and/or $\mathrm{OH}$ adsorption/desorption) and the hydrogen evolution are shifted to more positive potentials as the $\mathrm{pH}$ decreases by approximately $59 \mathrm{mV}$ per $\mathrm{pH}$ unit.

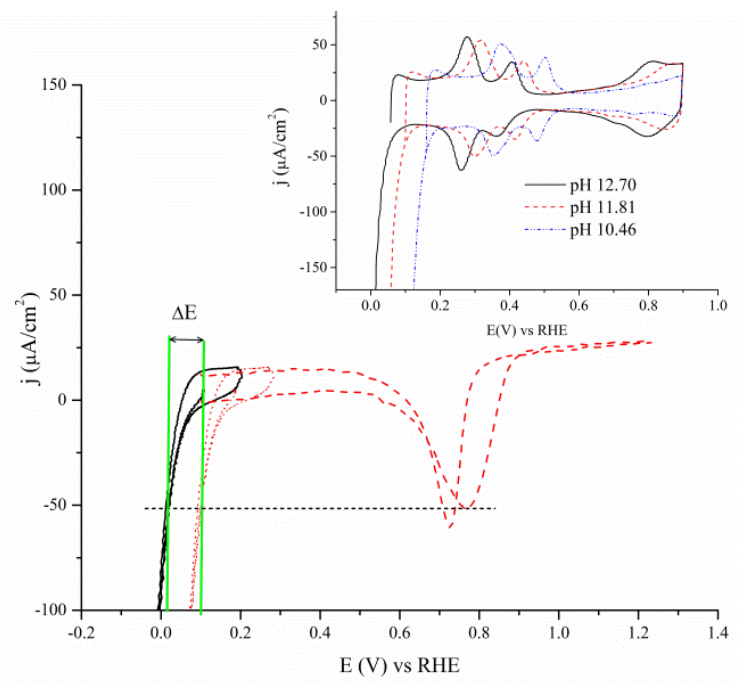

Figure 3. CV obtained at the ring for hydrogen evolution used as calibration curve (solid line) and currents on the ring at $0.1 \mathrm{~V}$ as a function of the disk potential, during ethanol oxidation on the disc (dashed line). CVs obtained at $10 \mathrm{mV} / \mathrm{s}$ and $1800 \mathrm{rpm}$. The dotted line corresponds to the ring CV displaced in the potential axis the amount of $\Delta \mathrm{E}$ such as the current at $0.1 \mathrm{~V}$ equals the maximum current measured at the ring during ethanol oxidation.

Experiments like those reported in Figure 3 were performed for different electrode rotation speeds in order to evaluate the effect of the mass transport on the local pH change of the electrode surface. The results for ethanol oxidation at the disc, currents at the ring and calibration curves for different rotation rates are presented in figure 4 . From the results plotted in figure $4 \mathrm{~A}$, it can be observed that ethanol oxidation current slightly increases with the rotation rate. These results are in agreement with previous reports [17] and show that the reaction is affected by mass transport limitations. The increase of the diffusion of species will provide more reactant to the electrode. This effect is also detected by the ring (Fig. 4B), where higher consumption of ethanol leads to higher protons production (or $\mathrm{OH}$ consumption) and, in consequence, more negative current densities. On the other hand, figure $4 \mathrm{C}$ shows that rotation rate does not affect the rate of hydrogen evolution, since at its onset, this reaction is controlled by rate of electron transfer and not by mass transport. It should be mentioned that reproducible results were obtained after repeating the measurements under identical conditions. However, cleaning of the electrode is required between measurements
During ethanol oxidation, poisoning species are formed on the electrode, leading to blockage of the surface. Before each new measurement in this study, both ring and disc potential have been cycled from 0.06 to $1.4 \mathrm{~V}$ to clean the surface until

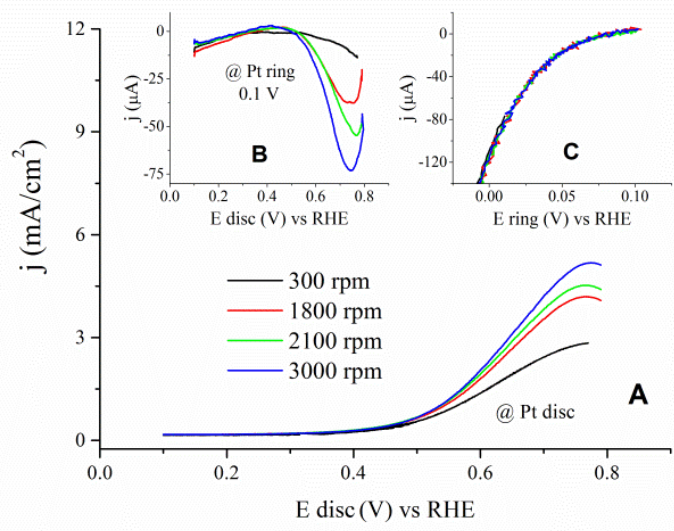

reproducible results are obtained."

Figure 4. A) $\mathrm{CV}$ obtained for $0.1 \mathrm{M}$ ethanol oxidation in $0.1 \mathrm{M} \mathrm{NaOH}$ at the $\mathrm{Pt}$ disc with different rotation speeds: 300, 1800, 2100 and $3000 \mathrm{rpm}$. Inset: currents obtained at the ring $B$ ) at $0.1 \mathrm{~V}$ during ethanol oxidation and $\mathrm{C}$ ) for hydrogen evolution at different rotations.

The results of the corresponding potential displacement for the measured currents and the $\mathrm{pH}$ variations at the interface are collected in Table 1. pH values were determined using equation 2 and the reported values correspond to the positive going sweep (that presents less negative currents).

Table 1. Results for the calculated potential displacements, $\mathrm{pH}$ change and interfacial $\mathrm{pH}$ for the ethanol oxidation in $0.1 \mathrm{M} \mathrm{NaOH}$ at different rotations speeds of the electrode.

\begin{tabular}{cccc}
\hline RPM & $\begin{array}{l}\mathrm{E} \\
\text { displacement } \\
(\mathrm{V})\end{array}$ & $\begin{array}{l}\mathrm{pH} \text { change } \pm \\
0.02\end{array}$ & $\begin{array}{l}\mathrm{pH} \text { at the } \\
\text { interface }\end{array}$ \\
\hline 300 & 0.055 & 1.00 & 12.00 \\
1800 & 0.076 & 1.29 & 11.71 \\
2100 & 0.084 & 1.42 & 11.58 \\
3000 & 0.088 & 1.49 & 11.51 \\
\hline
\end{tabular}

From the results reported in table 1, we can see that during ethanol oxidation, the maximum decrease of the local $\mathrm{pH}$ at the platinum electrode surface under the present conditions is about $1.5 \mathrm{pH}$ units. The change of the $\mathrm{pH}$ depends only slightly on the rotation speed, much less than expected from the variation of the ring currents. This is a consequence of the non-linear relation that exists between current and $\mathrm{pH}$ change. Currents from 15 to $75 \mu \mathrm{A}$ only correspond to a potential difference of $35 \mathrm{mV}(0.5 \mathrm{pH}$ units). In any case, the results show that the $\mathrm{pH}$ change during ethanol oxidation at $\mathrm{Pt}$ electrodes can be considered critical even under hydrodynamic conditions. 
Changes on the local $\mathrm{pH}$ at the interphase and their effect on the reaction rate have been reported before $[10,11,18]$. Significant distortions can be observed in the cyclic voltammograms of platinum electrodes in solutions with low buffer capacity $(3<\mathrm{pH}<11)$. These changes result from the alteration of the local $\mathrm{pH}$ at the electrode/electrolyte interphase induced by electrode processes such as hydrogen adsorption/evolution, hydrogen oxidation and Pt oxide formation (reaction involving $\mathrm{H}^{+}$or $\mathrm{OH}^{-}$as either reactants or products). Moreover, the authors [10] also showed that changes in the polarization curves for ORR can be observed induced by changes of interfacial $\mathrm{pH}$ due to the electrode reaction. These changes on the local $\mathrm{pH}$ of the electrode surface will alter the thermodynamics of the corresponding surface reactions as well as the surface state (e.g., adsorbate coverage, oxidation state and so on) with subsequent consequences in the kinetics of many electrode reactions.

The decrease of $1.49 \mathrm{pH}$ units demonstrated in this work is very significant, since experiments are performed under an experimental design that enhances mass transport. Hence, under thin layer configuration (as inside porous in fuel cells arrangements) this difference will reach higher values. According to Wang et al [9], who calculated the $\mathrm{pH}$ difference across an anion exchange membrane for direct methanol fuel cells, pH differences between the anode and the cathode can be as high as 4.1 units (the higher value found by the authors, at temperature of $800^{\circ} \mathrm{C}$ ) corresponding to a thermodynamic voltage loss of ca. $290 \mathrm{mV}$. Although this value may seem high it is not surprising at all if we have in mind that for $\mathrm{CO}_{2}$ being observed in IR experiment during ethanol oxidation in alkaline media (as reported in literature $[12,13]$ ), the $\mathrm{pH}$ at the thin layer solution needs to reach a value around 6 ( $\mathrm{pKa}$ for $\mathrm{CO}_{2}$ is 6.35). Under fuel cell conditions it is necessary to be particularly careful with transport control. Knowing that the $\mathrm{pH}$ of a solution of ethanol in water (fuel used in DEFCs) is around 7, with a low buffer capacity, and that at platinum electrodes the ethanol oxidation reaction is slowed down steeply at $\mathrm{pH}<11$ [19] we can predict low performances of the fuel cell due to high local $\mathrm{pH}$ changes on the electrode surface. Further studies of the local $\mathrm{pH}$ changes under thin layer configuration are being currently addressed in our group in order to have a more realist view of these differences in fuel cell measurements.

In conclusion, the RRDE measurements reported in this paper show that the local $\mathrm{pH}$ in the vicinity of $\mathrm{Pt}$ electrodes decreases during ethanol oxidation in alkaline media. The experiments were performed using flat electrodes under semiinfinite transport conditions. The decrease of the current measured at the ring when the potential is maintained at $0.1 \mathrm{~V}$ revealed a $\mathrm{pH}$ decrease of 1.30 units at the electrode interphase. As mentioned previously, the ethanol oxidation reaction is very sensitive to the $\mathrm{pH}$ and is slowed steeply at $\mathrm{pH}<11$ and $\mathrm{a} \mathrm{pH}$ decrease from 13 to around 11.7 due to the fast consumption of $\mathrm{OH}^{-}$species will certainly influence on the rate of the reaction at the electrode as well as in the adsorbate coverages and the formation of oxides at the surface.

This study clearly shows the need of careful consideration of these factors when analysing results from fuel cells measurements under alkaline conditions (with anion exchange membranes) because lower performances might be related (among other factors) with lower reaction rates caused by the $\mathrm{pH}$ decrease.

\section{Experimental Section}

Experiments were carried out at room temperature, in a typical three electrodes cell and under argon atmosphere (N50, Air Liquid). A platinum coil was used as counter electrode and a reversible hydrogen electrode as reference (RHE). Solutions were prepared using $\mathrm{NaOH}$ (pellets, for analysis, Merck), ethanol (Merck, p.a.), acetaldehyde (SigmaAldrich, ACS 99.5\%) and ultra-pure water (Elga-Purelab $18.2 \mathrm{M} \Omega \mathrm{cm}$ ). The working electrode was a ring-disc electrode from Pine Instruments (Pt ring and Pt disc) with a collection efficiency of $21.8 \%$. The electrode was conveniently cleaned by polishing with alumina powder $(0.05 \mu \mathrm{m})$ followed by sonication and rinsing with ultrapure water. Prior to each experiment, the potential of ring and disc electrodes was cycled between 0.05 and $1.5 \mathrm{~V}$ in $0.1 \mathrm{M} \mathrm{NaOH}$ until a stable cyclic voltammogram (CV) characteristic of the clean surface was obtained for both electrodes. Solutions at different $\mathrm{pH}$ for the calibration were prepared as described elsewhere [20]. Voltammetric curves were obtained with a bipotentiostat EG\&G Princeton Applied Research, Model 366A, a rotating device from Pine Instruments and a digital recorder eDAQ, ED401.

\section{Acknowledgements}

Financial support from Aalto University, Academy of Finland, MINECO and Generalitat Valenciana through projects CTQ2013-44083-P and PROMETEOII/2014/013 is acknowledged.

Keywords: local $\mathrm{pH} \bullet$ ethanol oxidation • platinum • fuel cells • Alkaline solutions

[1] A. Brouzgou, A. Podias, P. Tsiakaras, J. Appl. Electrochem. 2013, 43, 119 .

[2] T. N. Danks, R. C. T. Slade, J. R. Varcoe, J. Mater. Chem. 2003, 13 , 712 .

[3] K. Matsuoka, Y. Iriyama, T. Abe, M. Matsuoka, Z. Ogumi, J. Power Sources 2005, 150, 27-31.

[4] T. S. Zhao, Y. S. Li, S. Y. Shen, Front. Energy Power Eng. China 2010, 4, 443.

[5] R. Parsons, T. VanderNoot, J. Electroanal. Chem. 1988, 257, 9-45

[6] J. S. Spendelow, A. Wieckowski, Phys. Chem. Chem. Phys. 2007, 9, 2654.

[7] N. Ramaswamy, S. Mukerjee, Adv. Phys. Chem. 2012, 2012, 1.

[8] Y. Kiros, S. Schwartz, J. Power Sources 2000, 87, 101

[9] Y. Wang, L. Li, L. Hu, L. Zhuang, J. Lu, B. Xu, Electrochemistry Communications 2003, 5, 662.

[10] L. W. Liao, M. F. Li, J. Kang, D. Chen, Y. Chen, S. Ye, J Electroanal Chem 2013, 688, 207.

[11] M. Auinger, I. Katsounaros, J. C. Meier, S. O. Klemm,P. Biedermann, A. Topalov, M. Rohwerder, K. J. J. Mayrhofer, Phys. Chem. Chem. Phys., 2011, 13,16384

[12] A. Santasalo-Aarnio, E. Sairanen, R. M. Arán-Ais, M. C. Figueiredo, J. Hua, J. M. Feliu, J. Lehtonen, R. Karinen, T. Kallio, Journal of Catalysis 2014 $309,38$. 
[13] Z. Zhou, Q. Wang, J. Lin, N. Tian, S. Sun, Electrochim. Acta 2010, 55, 7995.

[14] K. Prater, A. Bard, J. Electrochem Soc. 1970, 117, 207

[15] A. Bard, L. Faulkner, Electrochemical Methods: Fundamentals and Applications 2001, p. 864

[16] H. Wang, Z. Jusy, R.J. Behm, J. Appl. Electrochem. 2006, 36, 1187

[17] M.C. Figueiredo, R.M. Arán-Aís, J.M. Feliu, K. Kontturi, T. Kallio, Journal of Catalysis 2014, 312, 78
[18] V. Lazarescu, J. Clavilier, Electrochim. Acta 1998, 44, 931.

[19] M. R. Tarasevich, O. V. Korchagin, Russian J. Electrochem. 2013, 49, 600

[20] R. Rizo, E. Sitta, E. Herrero, V. Climent, J. M. Feliu, Electrochim. Acta. 2015, doi:10.1016/j.electacta.2015.01.069 
Entry for the Table of Contents (Please choose one layout)

\section{COMMUNICATION}

By using rotating ring disc measurements, we reveal the existence of local $\mathrm{pH}$ changes in the vicinity of a Pt electrode during ethanol oxidation in alkaline media. This was achieved by measuring the increase of cathodic currents at the ring at a constant potential of $0.1 \mathrm{~V}$, caused by the shift of the equilibrium potential of the hydrogen evolution reaction. The experiments using in flat electrodes in contact with a relatively large bulk solution volume (in the electrochemical cell) revealed that the $\mathrm{pH}$ decrease at the interphase is $\mathbf{1 . 3 0}$ units. These results give a word of caution about the interpretation of experiments of ethanol oxidation at high $\mathrm{pH}$, especially when the systems are under constrained transport conditions like in fuel cells systems.

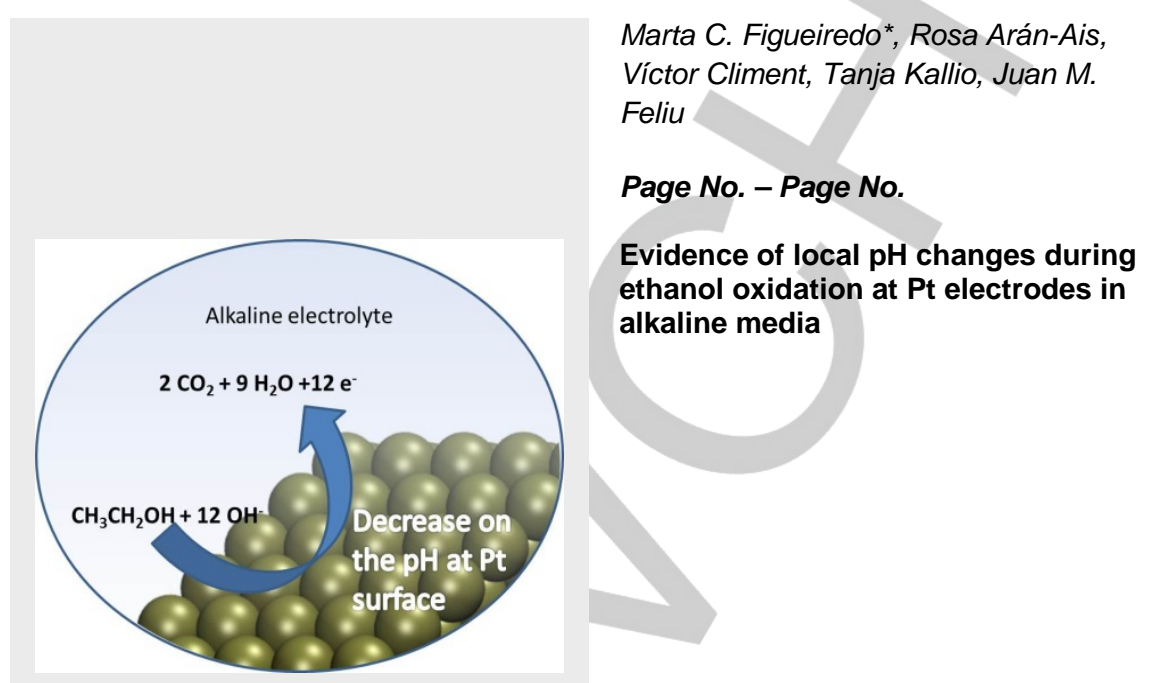

